\title{
Should technical aptitude evaluation become part of resident selection for surgical residency?
}

\author{
Muath Bishawi - Aurora D. Pryor
}

Received: 9 May 2014 / Accepted: 9 June 2014/Published online: 18 July 2014

(c) Springer Science+Business Media New York 2014

While it has been commonly thought that the surgeon's technical "talent" in the operating room is somehow linked with better patient outcomes, it was not until recently that this association has been reported in a large-scale study [1]. Birkmeyer et al. collected representative surgical videos from 20 bariatric surgeons in Michigan performing laparoscopic gastric bypass. The videos were blinded, peer evaluated, and scored based on technical aptitude. The surgical aptitude scores were strongly related to risk adjusted outcomes including a complication composite, operating times, re-admission, and overall mortality [1]. Interestingly, there was no association between the number of years in practice and the assigned technical aptitude score. This is a very important finding, given that it sheds light on a generally accepted belief among surgeons; some surgical talent cannot be taught or transferred, trainees either have it, or they do not. While this inherent ability is not necessary for all surgical procedures, findings from this study suggest that this ability may lead to a difference in outcome for technically demanding operations. This begs the question, should we be selecting applicants for surgical training that are more likely to possess this inherent ability?

Currently, the selection process of residents for surgical residency training, for the most part, comes down to five important components, (a) USMLE board examination scores (and/or in-service exam scores for fellows), (b) medical school performance, in particular, performance

\section{Bishawi ( $\square)$}

Department of Surgery, Stony Brook School of Medicine,

Stony Brook, NY, USA

e-mail: muath.bishawi@stonybrookmedicine.edu

A. D. Pryor

General Surgery Division, Bariatric and Metabolic Weight Loss Center, Stony Brook, NY 11794-8191, USA on surgical rotations, (c) strength and prestige of letters or recommendations, (d) research and other academic pursuits, and finally, (e) performance on the interview day $[2,3]$. The emphasis on one of these over another, despite some institutional variation, is for the most part standardized. For instance, in a large-scale recent study looking at selection criteria for general surgery applicants, the strongest emphasis was placed on the USMLE step 1 and the interview day [2]. The USMLE score, however, is often used for screening for interview selection, and those not meeting a minimum cut-off were most likely overlooked. In the study, which was a survey of program directors and departmental chairs, there was no mention of any testing for technical aptitude of any sort during the interview and/ or overall selection process. This is not to say that all interview days are the same. Some programs have instituted some unique components to their interview days including Mass General Hospital question and answer session, and some integrated surgical programs adding clinical scenario questions, and basic suturing and knot tying sessions. However, these efforts remain very sporadic, and not well studied.

The present attitude toward technical aptitude testing for candidate selection stems largely from the belief that differences in baseline abilities will no longer matter during the constant repetition of residency training. However, recent data suggest that while repetition leads to improvement over time (for some), the learning curve varies greatly based on baseline aptitude [3]. In a study by Buckley et al. [3], medical students that had higher baseline aptitude (visual spatial ability, depth perception, and psychomotor ability) were able to achieve proficiency with a laparoscopic suture simulator after a mean of 7 attempts, compared to only $30 \%$ of the lower aptitude students achieving similar proficiency after a mean of 14 attempts! 
Perhaps more interesting is the fact that $40 \%$ of the lower aptitude group never reached proficiency despite slight gradual improvements, with $30 \%$ of the group failing to progress at all. What is even more sobering is this was true in a study of resident's aptitude scores and their performance during complex operations [4].

Surgical simulators are becoming more wide spread today, with an increased adoption by many programs to help train surgical residents under controlled, low stress environments. Simulator labs are in fact required for ACGME certified surgical training programs. To date, research looking at the role of surgical simulation in resident and fellow training has been focused primarily on the concept of deliberate practice, which the focus on improving a specific skill through repetition and targeted feedback [5, 6]. For instance, in a recent randomized control trial, the use of a virtual reality simulator for laparoscopic cholecystectomy led to improved performance in the operating room [7]. The authors use these findings to suggest a possible role of implementing a simulation-based curriculum for surgical residency training [7]. However, a closer look at their data reveals that some individuals were scoring consistently higher even during the baseline runs, and some persistently scoring much lower. In fact, looking at most simulation-based studies in the surgical literature, this phenomenon is true.

More research is needed to help better understand the correlation of baseline aptitude testing with overall resident performance. Some of the skills required to become a successful resident are not necessary associated with spatial aptitude (e.g., organization, communication skills, etc.) However, eventually residency programs may use baseline aptitude testing as part of resident and fellow selection for two specific goals, (a) selecting for specific high aptitude individuals for sub-specialties that require high level of technical mastery (ex. bariatric surgery), or (b) selecting out individuals scoring poorly on visual spatial ability, depth perception, and psychomotor ability given that they may struggle in achieving proficiency during limited residency training time. This is especially important now given work hour restrictions and a constant push for further improving patient clinical outcomes and decreasing complications rates. The recent study by Birkmeyer et al. shows clearly that higher technical aptitude in the operating room translated into better outcomes and lower complications, yet we are failing to select for those individuals for our surgical residencies.

Disclosures Muath Bishawi and Dr. Aurora D. Pryor have no conflicts of interest or financial ties to disclose.

\section{References}

1. Birkmeyer JD, Finks JF, O'Reilly A et al (2013) Surgical skill and complication rates after bariatric surgery. $N$ Engl $J$ Med 369(15):1434-1442

2. Makdisi G, Takeuchi T, Rodriguez J, Rucinski J, Wise L (2011) How we select our residents-a survey of selection criteria in general surgery residents. J Surg Educ 68(1):67-72

3. Buckley CE, Kavanagh DO, Nugent E, Ryan D, Traynor OJ, Neary PC (2014) The impact of aptitude on the learning curve for laparoscopic suturing. Am J Surg 207(2):263-270

4. Wanzel KR, Hamstra SJ, Anastakis DJ, Matsumoto ED, Cusimano MD (2002) Effect of visual-spatial ability on learning of spatiallycomplex surgical skills. Lancet 359(9302):230-231

5. McDougall EM, Kolla SB, Santos RT et al (2009) Preliminary study of virtual reality and model simulation for learning laparoscopic suturing skills. J Urol 182(3):1018-1025

6. Diesen DL, Erhunmwunsee L, Bennett KM et al (2011) Effectiveness of laparoscopic computer simulator versus usage of box trainer for endoscopic surgery training of novices. J Surg Educ 68(4):282-289

7. Palter VN, Grantcharov TP (2014) Individualized deliberate practice on a virtual reality simulator improves technical performance of surgical novices in the operating room: a randomized controlled trial. Ann Surg 259(3):443-448 